\title{
Massive vitreous gel incarceration into the subretinal space following traumatic retinal detachment in a young patient: a case report
}

This article was published in the following Dove Press journal:

Clinical Ophthalmology

20 October 2011

Number of times this article has been viewed

\section{Takafumi Hirashima \\ Mihori Kita \\ Shin Yoshitake \\ Miou Hirose \\ Hideyasu Oh}

Department of Ophthalmology, Hyogo

Prefectural Amagasaki Hospital,

Amagasaki, Hyogo, Japan
Correspondence: Mihori Kita

Department of Ophthalmology, Hyogo

Prefectural Amagasaki Hospital

I-I-I Higashidaimotsu-cho, Amagasaki,

Hyogo 660-0828, Japan

Tel $+8 \mid 66482$ I52I

Fax +8I 664827430

Email mihorik@kuhp.kyoto-u.ac.jp
Purpose: This paper reports a young patient with a traumatic rhegmatogenous retinal detachment and massive vitreous gel incarceration into the subretinal space, who was successfully treated with 23-gauge transconjunctival vitrectomy.

Case report: An 11-year-old boy was referred to the authors' clinic with traumatic retinal detachment in the right eye, 2 weeks after ocular contusion in a baseball accident. At the time of the injury, emergency fundus examination by his local doctor had revealed vitreous hemorrhage in the inferior quadrant of the right eye. Visual acuity was 1.5 . He had continued to play baseball as usual for 2 weeks after the injury. At his first visit to the authors' clinic, fundus examination showed a highly bullous retinal detachment involving the inferior two quadrants, associated with multiple irregular retinal breaks. There was an oval hole in the inferior quadrant which was 10 -disc diameter $\times 5$-disc diameter in size and was surrounded by edematous and hemorrhagic retina. The macula remained attached. Absolute rest for 4 hours in the supine position with binocular occlusion did not diminish the height of the retinal detachment. A 23 -gauge three-port pars plana vitrectomy combined with $360^{\circ}$ circumferential buckling was performed under general anesthesia. The lens was retained. Incarceration of massive vitreous gel, including vitreous hemorrhage into the subretinal space through the largest break, was observed during vitrectomy. Reattachment of the retina was achieved by fluid-air exchange and internal tamponade using $\mathrm{SF}_{6}$ gas. At follow-up at 9 months, the retina remained attached and visual acuity in the right eye was 1.2 .

Keywords: retinal detachment, trauma, contusion, vitrectomy

\section{Introduction}

Trauma, especially that caused by sporting accidents, is recognized as one of the most common etiologies of retinal detachment at a young age ${ }^{1-3}$ Blunt injury to the eye results in both direct tissue damage at the site of impact and indirect tissue damage to distant intraocular tissues by transmitted forces. ${ }^{4-9}$ This type of closed globe injury is a well-recognized cause of rhegmatogenous retinal detachment, causing $10 \%-15 \%$ of such injuries. ${ }^{1,4,6}$

This paper presents an unusual case of traumatic retinal detachment caused by necrotic retinal breaks with massive vitreous gel incarceration into the subretinal space.

\section{Case report}

An 11-year-old boy was referred to the authors' clinic with traumatic retinal detachment in the right eye, 2 weeks after ocular contusion from being hit by a 
baseball. Emergency fundus examination by his local doctor at the time of injury had revealed vitreous hemorrhage in the inferior quadrant of the right eye. Visual acuity had been 1.5 without refractive correction. He had continued to play baseball as usual.

At his first visit to the authors' clinic, best corrected visual acuity in the right eye was 1.0, and intraocular pressure was $13 \mathrm{mmHg}$. Slit-lamp examination revealed an intact cornea, round pupil, and clear lens with no penetrating wound of the eye wall, iridocyclitis, hyphema, angle recession, fibrin exudates, or signs of infection. Fundus examination showed bullous retinal detachment in the inferior two quadrants associated with multiple irregular retinal breaks. There was an oval hole in the inferior quadrant with rolled and ragged edges, which was 10 -disc diameter $\times 5$-disc diameter in size and was surrounded by edematous and hemorrhagic retina (Figure 1). There was no retinal break in the superior hemisphere. The macula remained attached without edema, hemorrhage, choroidal rupture, or hole formation. The vitreous hemorrhage was almost absorbed. There were no abnormalities in the left eye. Absolute rest for 4 hours in the supine position with binocular occlusion did not diminish the height of the retinal detachment.

The patient subsequently underwent repair of the retinal detachment. A 23-gauge three-port pars plana vitrectomy combined with $360^{\circ}$ circumferential buckling was performed under general anesthesia. The lens was retained. Posterior vitreous detachment was achieved with a hyaloid lifter using a wide-angle viewing system. Residual hyaloid cortex at the posterior pole was removed using a retinal brush

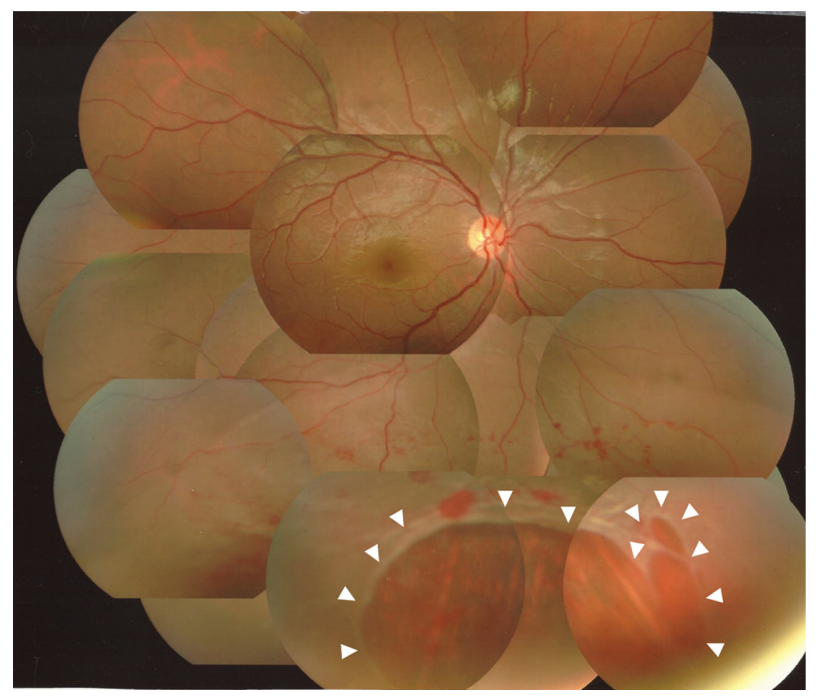

Figure I Photograph of the fundus of the right eye at the first visit. Note the bullous retinal detachment in the inferior two quadrants. There are multiple irregular retinal breaks (arrowheads), surrounded by edematous and hemorrhagic retina.
(Vit Sweeper; Inami and Co, Ltd, Tokyo, Japan) with the aid of triamcinolone acetonide $\left(\mathrm{MaQaid}^{\circledR}\right.$; Wakamoto, Tokyo, Japan). Massive incarceration of vitreous gel including vitreous hemorrhage into the subretinal space through the largest break was observed. Peripheral vitrectomy was performed with endoscopic guidance. Flattening of the retina was achieved by fluid-air exchange and internal drainage through the original breaks. Retinopexy with endolaser and supplementary transscleral cryopexy was applied around the breaks. The vitreous cavity was filled with $20 \% \mathrm{SF}_{6}$ gas as internal tamponade. The patient was encouraged to maintain a face-down position for 2 weeks. No intraoperative complications were encountered.

At the 9-month follow-up, the retina remained attached (Figure 2) and best corrected visual acuity in the right eye was 1.2 with myopia of 1.0 diopters. The lens had neither subcapsular opacity nor nuclear sclerosis.

\section{Discussion}

It has been reported that $10 \%-15 \%$ of cases of retinal detachment are caused by contusion. ${ }^{1,4,6}$ Retinal breaks due to contusion are most commonly produced by traction at the borders of the vitreous base. However, some contused eyes develop retinal breaks in areas with no apparent vitreous attachment. The breaks tend to be large irregular holes with ragged edges, and are frequently associated with vitreous and retinal hemorrhage, retinal edema, and severe underlying choroidal degeneration. Such breaks are commonly in the inferotemporal quadrant, which is the most frequent site of direct impact. ${ }^{1,2,4,9}$ In this case, irregular retinal breaks surrounding

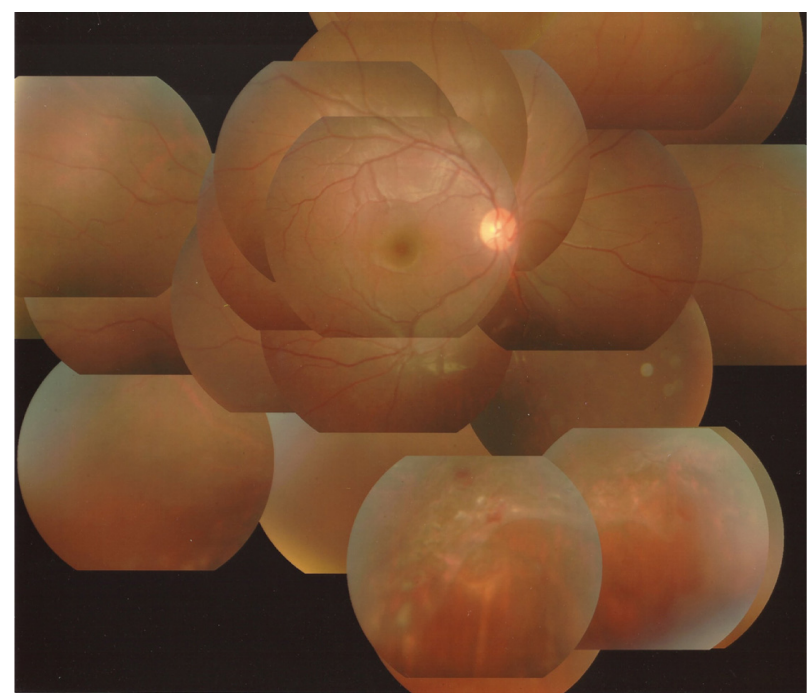

Figure 2 Photograph of the fundus of the right eye postoperatively. The entire retina is reattached. 
the retinal hemorrhage and edema are likely to have arisen within necrotic retina at the site of scleral impact.

Laboratory experiments have shown that retinal breaks responsible for traumatic retinal detachment are formed at the time of injury. ${ }^{4,8}$, This observation is difficult to confirm clinically, as patients who develop traumatic retinal detachment rarely present for peripheral retinal examination immediately after the injury. For example, Cox et al reported that $12 \%$ of traumatic breaks or retinal detachments occurred immediately and 30\% occurred within 1 month of injury. ${ }^{4}$ Johnston reported that immediate retinal detachment is a feature of necrotic retinal breaks, while oral dialysis leads to a slow accumulation of subretinal fluid. ${ }^{9}$ Vitreous hemorrhage may initially have obscured the view of the retinal breaks and detachment in the patient discussed here.

Traditionally, scleral buckling has been considered the procedure of choice for treatment of rhegmatogenous retinal detachment, especially in young patients. ${ }^{10}$ This case showed a balloon-like retinal detachment, which is not common in young patients because there is not much liquefaction of the vitreous gel. The massive vitreous gel incarceration into the subretinal space prevented a decrease in height of the retinal detachment even with restrictive preoperative rest. The delay in diagnosis of retinal detachment allowed him to continue to play baseball after the injury, which caused massive vitreous incarceration into the subretinal space through large retinal breaks. In this situation, external drainage with scleral buckling would have been dangerous because it might have caused vitreous gel herniation into the scleral wounds, leading to vitreous traction to the retina. This case was successfully managed with primary 23-gauge pars-plana vitrectomy combined with encircling buckling, preserving the lens.

The result of preoperative absolute rest seems valuable in deciding on treatment modalities for retinal detachment. When the height of detachment is not reduced by restrictive rest, there may be vitreous gel incarceration into the subretinal space, and primary vitrectomy may be indicated.

\section{Disclosure}

The authors declare no conflicts of interest in this work.

\section{References}

1. Goffstein R, Burton TC. Differentiating traumatic from nontraumatic retinal detachment. Ophthalmology. 1982;89:361-368.

2. Nakanishi H, Kita M, Otsu Y, Amemiya K, Kawamoto T, Matsumoto M. Clinical features and surgical outcome of traumatic retinal detachment. Jpn J Clin Ophthalmol. 2006;60:959-965.

3. Sarrazin L, Averbukh E, Halpert M, Hemo I, Rumelt S. Traumatic pediatric retinal detachment: a comparison between open and closed globe injuries. Am J Ophthalmol. 2004;137:1042-1049.

4. Cox MS, Schepens CL, Freeman HM. Retinal detachment due to ocular contusion. Arch Ophthalmol. 1966;76:678-685.

5. Delori F, Pomerantzeff O, Cox MS. Deformation of the globe under high speed impact: its relation to contusion injuries. Invest Ophthalmol. 1969;8:290-301.

6. Eagling EM. Ocular damage after blunt trauma to the eye. Its relationship to the nature of the injury. Br J Ophthalmol. 1974;58:126-140.

7. Wiedenthal DT, Schepens CL. Peripheral fundus changes associated with ocular contusion. Am J Ophthalmol. 1966;62:465-477.

8. Cooling RJ. Traumatic retinal detachment-mechanisms and management. Trans Ophthalmol Soc UK. 1986;105(Pt 5):575-579.

9. Johnston PB. Traumatic retinal detachment. Br J Ophthalmol. 1991;75:18-21.

10. Schwartz SG, Mieler WF. Management of primary rhegmatogenous retinal detachment. Comp Ophthalmol Update. 2004;5:285-294.
Clinical Ophthalmology

\section{Publish your work in this journal}

Clinical Ophthalmology is an international, peer-reviewed journal covering all subspecialties within ophthalmology. Key topics include: Optometry; Visual science; Pharmacology and drug therapy in eye diseases; Basic Sciences; Primary and Secondary eye care; Patient Safety and Quality of Care Improvements. This journal is indexed on

Submit your manuscript here: http://www.dovepress.com/clinical-ophthalmology-journal

\section{Dovepress}

PubMed Central and CAS, and is the official journal of The Society of Clinical Ophthalmology (SCO). The manuscript management system is completely online and includes a very quick and fair peer-review system, which is all easy to use. Visit http://www.dovepress.com/ testimonials.php to read real quotes from published authors. 